Wilfrid Laurier University

Scholars Commons @ Laurier

Lyle S. Hallman Social Work Faculty

Publications

Lyle S. Hallman Faculty of Social Work

2003

\title{
The Effects of Negative Legacies on the Adjustment of Parentally Bereaved Children and Adolescents
}

\author{
Phyllis R. Silverman \\ Massachusetts General Hospital, Harvard Medical School \\ John Baker \\ Cambridge City Hospital, Harvard Medical School \\ Cheryl-Anne Cait \\ Wilfrid Laurier University, ccait@wlu.ca \\ Kathrin Boerner \\ Lighthouse International
}

Follow this and additional works at: https://scholars.wlu.ca/scwk_faculty

\section{Recommended Citation}

Silverman, Phyllis R.; Baker, John; Cait, Cheryl-Anne; and Boerner, Kathrin, "The Effects of Negative Legacies on the Adjustment of Parentally Bereaved Children and Adolescents" (2003). Lyle S. Hallman Social Work Faculty Publications. 3.

https://scholars.wlu.ca/scwk_faculty/3

This Article is brought to you for free and open access by the Lyle S. Hallman Faculty of Social Work at Scholars Commons @ Laurier. It has been accepted for inclusion in Lyle S. Hallman Social Work Faculty Publications by an authorized administrator of Scholars Commons @ Laurier. For more information, please contact scholarscommons@wlu.ca. 
OMEGA, Vol. 46(4) 335-352, 2002-2003

\title{
THE EFFECTS OF NEGATIVE LEGACIES ON THE ADJUSTMENT OF PARENTALLY BEREAVED CHILDREN AND ADOLESCENTS
}

PHYLLIS R. SILVERMAN, PH.D.

Massachusetts General Hospital, Harvard Medical School

JOHN BAKER, PH.D.

Cambridge City Hospital, Harvard Medical School

CHERYL-ANNE CAIT, PH.D.

Faculty of Social Work, Wilfrid Laurier University

KATHRIN BOERNER, PH.D.

Lighthouse International, New York

\begin{abstract}
This is a report of a qualitative analysis of a sample of bereaved families in which one parent died and in which children scored in the clinical range on the Child Behavior Check List. The purpose of this analysis was to learn more about the lives of these children. They were considered to be at risk of developing emotional and behavioral problems associated with the death. We discovered that many of these "high risk" children had a continuing bond with the deceased that was primarily negative and troubling for them in contrast to a comparison group of children not at risk from the same study. Five types of legacies, not mutually exclusive, were identified: health related, role related, personal qualities, legacy of blame, and an emotional legacy. Coping behavior on the part of the surviving parent seemed to make a difference in whether or not a legacy was experienced as negative.
\end{abstract}




\section{INTRODUCTION}

Stress is an almost universal response in families with dependent children after the death of a parent (Rutter, 1983; Silverman \& Worden, 1993). In addition, there is more and more evidence that the death of a parent puts some of these surviving children, than would be expected by chance, at risk of developing emotional problems (Worden \& Silverman, 1996). Gersten and her colleagues (1991) found that children were at greater risk of developing major depression but not conduct disorders after their parents' death. However, there is little consensus about what leads to problem behavior in these children.

While stress may be one factor by itself, it does not account for this outcome. Worden and Silverman (1993) found that parental depression and their feelings of stress were associated with problem behavior in the bereaved children they studied. Factors such as the nature of the death have been considered, but found to be inconclusive. For example, Saldinger and her colleagues (1999) found that children whose parent's died after a prolonged illness had poorer outcomes in comparison to children whose parent's death was unanticipated. Worden and Silverman (1996) found that sudden death put children at greater risk during the first year after the death. These findings point to the importance of the family context on bereaved children's behavior (Silverman, 2000a; Silverman \& Worden, 1992).

This article reports on the findings of a qualitative analysis of a sub-sample of children who participated in the Harvard/MGH Child Bereavement Study. These children were identified, on the Child Behavior Check list (Achenbach, 1983), as displaying problematic behavior associated with serious emotional problems. The purpose of this analysis was to learn more about these children's lives and what might be associated with their elevated test scores.

\section{STUDY POPULATION}

The children and families reported on in this article were chosen from the larger Harvard/MGH Child Bereavement Study (CBS) (Silverman, 2000a; Silverman \& Worden, 1992, 1993; Worden, 1996; Worden \& Silverman, 1996). The Harvard/MGH CBS, was a longitudinal study designed to look at the consequences of the death of one of their parents for children between the ages of 6 and 17. A nonclinical sample of 67 families with 120 children was recruited. The families, of diverse socioeconomic, religious, and ethnic backgrounds, were interviewed in their own homes at 4, 13, and 24 months after the death. In the target communities, 51 percent of the eligible families agreed to participate. The sample consisted of an almost equal number of boys and girls whose average age was 11.8 years. Seventy-two percent lost their father and 28 percent their mother. Sixty percent of the parents had been ill for some time before the death and the rest died suddenly. The modal number of children in a family was two while nine families 
had only one child. A matched control group of non-bereaved children was also interviewed to establish if those children whose parent died were more likely to develop emotional problems.

A semi-structured interview with the surviving parent was used to gather information about family demography, pre-death status, circumstances of the death, mourning behavior, current support, stress and coping, concerns about the children, family activities, and responses to the death including talk about the deceased. A similar interview outline was followed with the children (Silverman $\&$ Worden, 1992). All the interviews were audiotaped. In addition to interviews, both parents and children responded to several standardized measures. Parents filled out the Child Behavior Check List (CBCL) (Achenbach, 1983), and the Center for Epidemiological Studies Depression (CES-D) assessment (Radloff, 1977). Children filled out the Harter Perceived Competence Scale (Harter, 1985).

The CBCL scores were used to assign children at all three time periods to risk categories. Children whose T-scores on this inventory of emotional/behavior problems exceeded 64, were considered at risk; that is, based on this score their problems warranted consideration for mental health care (Achenbach, 1983; Silverman \& Worden, 1993; Worden \& Silverman, 1996). Two years after the death, 20 percent of the bereaved children had elevated scores on the CBCL, as compared to 9 percent of the non-bereaved population (Worden \& Silverman, 1996).

The present analysis used a qualitative approach following the procedures recommended by Strauss and Corbin (1990) to lead us to an understanding of the bereavement process that was grounded in the data (Glaser \& Strauss, 1967). We focused on a small sample of children and their families. These families were chosen because they had at least one child whose CBCL scores identified him or her as having problems in the clinical range. We began our qualitative analysis by focusing on two families who met this criteria. All four authors read the interviews independently, and when no transcription was available, we listened to the audiotapes. We read or listened to all three interviews, over the three time periods that the family participated in the study, following a pre-agreed-upon outline for abstracting key data from each interview. We sorted the data on the following relevant themes: descriptions of the deceased, descriptions of their relationship with the deceased and their surviving parent, description of themselves, their reflection on the meaning of the death in their family, and their relationships with friends and other family members. The surviving parents' interviews were examined for how they talked about the deceased, how they understood their children's behavior and reactions to the death, as well as their understanding of their children's needs. These themes reflected the areas covered in the respective interviews that focused on the family's social context and their relationship to each other and to the deceased as well (Silverman \& Nickman, 1996; Silverman \& Worden, 1992, 1993). The authors met weekly to compare what we were learning and to be sure that we were all abstracting the same data in each category. The 
authors brought extensive clinical experience as well as training in child development and family theory to the analysis (Silverman, 2000b).

As we began to identify common themes in the data, we added new families to see if the same themes emerged. In keeping with grounded theory (Glaser \& Strauss, 1967), we each read and organized the data independent of the others to see if as we added new cases they supported our earlier findings. We then reviewed together what we found and challenged each other to ensure that we were identifying common themes.

We stopped adding families when we felt that we were no longer learning anything new from the data. In total we reviewed 12 families in which at least one child had an elevated CBCL score. There were 28 children in these families, 20 of whom had scored in the clinical range by the final interview in the study. Clearly there were also children in all of these families who did not have elevated scores. While we identified factors that might differentiate them from their siblings, we are leaving this for another article.

The children's ages ranged from 6 years to 16 . Half the children were over 13 . The proportion of boys and girls in this sample matched that of the larger sample, as did the proportion of fathers who died compared to mothers. For purposes of comparison we included seven families where none of the children were at risk, matching at least one of them for the sex and ages of the at-risk children, as well as for the gender of the parent who died.

\section{FINDINGS}

We did not anticipate the direction in which the findings took us. As we began to identify patterns in the data that repeated themselves, we discovered that the high risk children had a particular kind of relationship to their deceased parent. This relationship was difficult or uncomfortable for them. We recognized this as another side of the concept of living legacy first used by Normand (1994) in an earlier analysis of data from the Child Bereavement Study. She found that children, with what appeared to be careful consideration, chose aspects of the deceased's personality or behavior that connected them to their dead parent. While initially many of the children in her sample reached out and talked to the deceased, with time these conversations were internalized and these children saw themselves as what Normand called "a living legacy" for their parent. They experienced this as a very positive connection, giving them comfort and solace.

In this new analysis we found a connection that was negative and did not provide the children, at the point in time in which we found them, with reassurance support or comfort. These children were not able to reflect on their behavior, given their ages and the cognitive ability expected for their age.

We found that these children at risk had a relationship to the deceased that, for one reason or another, caused them to worry, feel burdened, and/or be fearful. This was related to the deceased's life, illness or death, and/or his or her relationship 
with this child. These legacies by themselves did not predict problems for the children. They appeared in both those with elevated scores and non-elevated scores. As we looked at the surviving parent's reactions, we found that these were critical in understanding the impact of this connection on the child. The parent-child interaction determined whether or not the legacy had negative meaning for the child. To some extent we are talking about the parent's ability to reflect on their own behavior and its consequences for their children.

We will report on our findings in two parts. The first part will describe a typology of negative legacies suggested by the data, and that occurred in more than one family. The second part focuses on responses to these legacies by their surviving parent, that either eased the child's difficulty or compounded it. Threaded throughout the article are examples from children whose scores on the CBCL were not elevated and who served as a comparison group in this qualitative analysis of the data.

\section{Types of Legacies}

Five kinds of legacies were identified. These were not mutually exclusive. Often several types were found in one family, and these were sufficiently different in their themes to justify reporting on each of them separately.

\section{Physical or Health Related Legacy}

A physical or health legacy connects directly to the illness that caused the parent's death. It reflects the child's fear or sense that he or she will die from the same condition or disease that killed his/her parent. Many of these children had watched the parent's decline over several years. Children who were in the low risk group had similar concerns.

Ten year old Keith, whose CBCL score was not elevated and whose father was first diagnosed with cancer shortly after his birth, expressed his fear when he asked his mother:

\section{Is what killed daddy contagious?}

Ruth, age 15, and whose CBCL scores were always in the low range, was fearful about her risk of getting cancer. Her mother talked about this fear:

I think sometimes if Ruth is not feeling well, she has a pain in her stomach, she wants me to take her to the doctor so he can tell her that she does not have cancer. I think that she is afraid that she is going to be the next one.

In contrast Claire, whose score was not elevated, would not allow herself to find out if she really was in danger. She was 13 when her father died. She was a gifted student and had been very involved in school sports. In the third interview she reported: 


\section{SILVERMAN ET AL.}

I won't go to the doctor. This year, I dropped out of sports at school rather than have a physical. I am sure he will tell me that I have a tumor. My mother says I don't have to worry but she is wrong.

The illness that killed their parent is clearly present in these children's lives, but manifests itself differently in each of them: Ruth is willing to be reassured by the doctor, Claire will not go and allows her fears to interfere with her other activity.

\section{Role Related Legacy}

There were children who felt that they needed to fill the space their parent left by assuming the deceased's role in the family. Some did this by providing what we called "emotional support" for other family members. For example, Tony, whose score was not elevated, talked about his dreams in which his father talks to him:

You are the man of the house. He tells me to take care of my mother, brother and sister. I feel like he's watching over me; helping me out some of the time.

Tony describes helping with chores around the house and trying to be especially helpful to his brother who he recognized as not having as much time with his father. He assumes his father's role in worrying about his mother and trying to partner with her in caring for his siblings.

Lisa, considered at risk, actually assumed responsibility for doing the work of the deceased, and this became her primary role in the family. She was 15 when her mother died from an accidental overdose of anti-depressant medication, and describes how her role as parent surrogate increased over the two years since her mother's death. When asked about what is most difficult about her mother's death, she explains:

Trying to get used to being the only female around the house. And cleaning and doing all the chores and everything .... I don't have anybody to talk to about like, woman things. Usually she (mother) would like, during a fight or something, my mother would come right in and fix everything up. I usually have to help now. . . . If my brothers are fighting, I usually walk in and yell at them.

Ten-year-old Frank, who was in the at-risk group, tried to keep up his father's vegetable garden for the first year after his father's sudden death. Little of his connection to his father sounds negative. It is only later as we look at his mother's reaction does this become clear. Frank recalled that he wanted to teach his younger sister what he learned from his father about trains and do other things his father did in their home:

I'm very proud to do things my dad would do. I'm like him. My mother didn't believe I could fix the disposal and I did. I try to do things to please my father. I take care of my mother and sister and I try to be prepared for anything. I see myself as a person that has to help out more than normal because somebody in 
the family left, died, and I must help my mom more than I would if my father was alive.

\section{Personal Qualities}

There were children who identified themselves with personal qualities that they saw in their deceased parent. These were qualities that were adopted by the children that made them more like their parent, or alternatively, qualities that they deliberately rejected so as not to be like the deceased parent. For example, 16-year-old Rita, with an elevated score, wanted to separate herself from her father. She talked about how much academic achievement meant to her father, how proud he was of his Ph.D., and how sad it was that he lost much of this ability as a result of his lengthy illness. She dropped out of school rather than devote herself to her studies. She said if she didn't understand what the teacher was saying, she saw no reason to struggle with the material: I'm not like my father.

Other children also picked up on the personal qualities in their parent that reflected positive qualities. Frank remembered his father:

My father was generous. I am generous too. I am like him in many ways.

In contrast, John, Tony's younger brother, was nine when his father died in an alcoholic stupor, and his CBCL scores were elevated at all three times. John highlighted both the physical and the emotional likeness between himself and his father. He describes himself:

I am just like my father. I'm smart like he was, I'm short, we have the same color hair. I have his bad temper too. I see myself in him. I am reminded when I look in the mirror.

\section{Legacy of Blame}

There were children who remained connected to the deceased by holding on to a sense that the family, either they, or their surviving parent had not done enough for the deceased and that this led to his or her death. This sense of blame is often associated with a sense of guilt.

Lisa blames her father because he decided to take her mother off life supports. Lisa felt guilty because she didn't tell her mother how much she loved her.

In Rita's family, her younger sister Susan often took care of her father after school during his long illness. Susan reported feeling sad and angry after her father's last hospitalization, and wondered:

Maybe I didn't take good enough care of him. The nurses gave him the wrong medicine. 


\section{Emotional Legacy}

There were those children who seemed to have an emotional connection to the deceased. This type of connection is difficult to separate out from other types of legacies. However, sometimes what was passed on from the deceased parent was not just a personal quality, but the broader emotional atmosphere of the parent's life or of the home prior to the death. As mentioned above, often guilt and blame were aspects of this connection. Each family in some way had their own emotional shadow left by the quality of the deceased's emotional well being or by his or her illness.

Jodie was 16 when her mother died of breast cancer at the same age as her maternal grandmother who had died of the same disease. Two years after her mother's death, Jodie recalled:

I took care of my mother. She was very clear that she didn't want me to have to take care of my brothers and sister as she did when her mother died. I was with her, I bathed her, and changed her clothes. I watched her pain. I am afraid of dying, of the pain. It is with me all the time.

From time to time before her mother's death, Jodie would run away from home. In some way, by running away, she was following mother's advice to not have to take care of her siblings. She also avoided watching her mother's pain.

Her father describes Jody's sister Vickie, who was also considered at risk, two years after their mother's death. Vickie chose a different way of dealing with her reactions to her mother's death. Father said:

She has difficulty trusting others. I was lucky I could get her into a mental hospital. She was using drugs and was caught in a stolen car. She doesn't feel good about herself. I think she feels guilty because she ran away a lot because mother was ill. She has a lot of issues of trust. Everytime she trusts someone, they hurt her. I think it is connected to her mother "leaving."

When children describe having personal qualities like their parent, they are also acknowledging an emotional legacy that can be both hurtful and helpful to them.

In summary, we see a range of behaviors in the children that kept them connected to the deceased. How these connections were recognized and understood depended on the surviving parent's reactions. The next section of this article describes their parents' responses.

\section{Influence of the Surviving Parent's Response}

Our analysis showed that the surviving parent's way of coping with the death was an essential factor, although not the only factor, in determining if these legacies had a negative influence on the lives of these children. This does not mean that the parent is to blame, but rather that children's reactions cannot be understood without examining their interaction with their surviving parent. 
In looking at parental reactions, it seems that their awareness of their children's concerns was related to their own ability to recognize and respond to the issues and take their children's point of view. Allen and Hayslip (2000) developed the concept of "experienced competence," which refers to the ability of the individual to be an active agent in finding solutions to a new situation. It appeared that some parents did not know how to actively cope in a way that would be helpful to their children (Ayers, Sandler, West, \& Roosa, 1996; Boerner \& Silverman, 2001; Christ, 2000; Silverman, 2000a). They did not always find effective problem solving techniques.

Parental reactions varied. We identified the following patterns in their behavior: 1) reframing the problem; 2) giving the problem a name; 3) dismissing or minimizing their child's reactions and as a result invalidating them; 4) ignoring what the child was doing or saying; and 5) feeling totally helpless to do anything about the situation. These are not mutually exclusive categories, and parents often displayed more than one type of reaction. We found that children with low CBCL scores were more likely to have parents who could reframe the problem and or give it a name in a positive way. There were children in the same family who were at risk and others who were not. In these families parents had a different relationship with each child and further analysis of the data will tell us more about these children.

\section{Reframing the Problem}

Parents who reframed a problem tried to look at it in a new light; that is, from another point of view. Instead of focusing on all of the problematic aspects of the deceased parent's behavior, for example, they looked for positive aspects in the situation. When Ruth expressed her fears about her own health, mother responded to her request to go to the doctor and let him see what is going on. She respected her child's fear and framed it in a way that Ruth was not left feeling helpless. Ruth's mother and father were divorced. Her mother agreed to father's request that he could die in her home which they once shared. Mother thought it was important to Ruth to see the positive aspects of her parents relationship. This was another example of putting her child's needs first.

Kimball, nine when his father died, was not at risk. His father had been chronically depressed. Kimball had found his father right after he died. Initially it looked as if he may have committed suicide, but the medical examiner determined that he had aspirated on his medication. Mother was relieved that the family no longer had to live in the shadow of his emotional illness. Mother feared that Kimball could feel that he had caused the death, or that he might blame her instead. She recognized that his grief would be different from hers. From the beginning she reframed the experience by helping him see the good in his father as well.

I told him to think of Daddy in heaven smiling at us. I encouraged him to develop his musical ability that he got from his father. I was very clear in how 
I explained to him, that what happened to his father was an accident, that could have happened to anyone and we weren't responsible.

In talking about the circumstances, she helped Kimball sort out the reality of what happened and develop a positive memory of his father. She reframed the meaning of the death in a way that a nine-year-old could understand.

\section{Giving the Problem a Name}

Another way parents coped with a problematic legacy was to give the problem a name, and thus help the children to separate themselves from the problem. If something has a name, then it is possible to talk about it, to find a way of understanding it. It makes it possible to remember the good and the bad and to integrate both aspects of the parent into the child's picture of him or her.

Tony's mother was an active member of AL-Anon, and was able to explain to her children that their father's drinking was an illness. Tony describes what she said:

My mother always tells me that my father was two people, one when he was drunk and one when he was sober. I resented the person that was under the alcoholism, when he was drunk. I knew that the alcoholism wasn't him. I was sorry that he was stricken with the disease.

The children could easily identify father's behavior with this illness and the danger it held for them as well. They had a name, they knew what to call it.

John, who was at risk, was 10 and the youngest child in the family. He told the interviewer about the danger of drinking. But mother redefined the consequences of John and father being alike:

Oh, God, he's just like him (father). Everything like Dad. He has his father's personality ... he could become a drinker someday. One of the reasons we started counseling is we were exhausted giving John all our attention.

In this instance we see the negative consequences for John as his mother identified him with his father's problem.

We see the negative consequences for Lisa whose father could not give his wife's illness a name. His wife suffered from clinical depression. Lisa, who was at risk, thought her mother died because the doctor medicated mother inappropriately. Without a name for mother's condition, Lisa had no way of making sense out of what had happened. Father saw no need to tell the children that mother was ill and that was why she had all this medication.

\section{Dismissive and Minimizing Behaviors}

Some parents tried to minimize the legacy associated with the parent's death. They were unable to understand their children's feelings and legitimate them. 
They also unwittingly failed to moderate the negative consequences of the legacy for the children and these were children all of whom were at risk.

Lisa told her father very clearly that her mother had told the children that her problems were a result of her having too many children. Father told the interviewer that he and mother argued a good deal about her favoring the boys over Lisa and the children heard this. Instead of acknowledging these realities as Lisa heard them, father tried to reassure her that mother really did love her.

\begin{abstract}
I tried to bring the subject up to her and say "why do you say that mama hated you or hated us, or hated children?" She says, "well she did." I say "Mama loved you and me and everybody very much." I said "it kills her when you talk like that. You know you couldn't beat her as a mother when kids were babies and so on." At that point she sort of tuned me out.
\end{abstract}

Father was denying the reality that both of them were aware of. Saying "mother loved you" might sound reassuring to him, but it was minimizing Lisa's concern and in essence delegitimating her awareness of reality. At the same time, Lisa was working hard to fill her mother's role in the family. Again father did not fully understand her behavior but simply said:

I didn't ask her to do all this work. It is her choice.

Thus, he minimizes the significance, for Lisa, and does not recognize that her behavior could have other meanings.

Claire's mother is also minimizing her daughter's concern when she tells Claire that she need not worry about getting a brain tumor like her father did. By saying this she is trying to minimize the importance of the illness in Claire's life. Claire's behavior (i.e. dropping out of sports because she would have to get a physical examination) shows that her fear is very real.

Frank tried to keep his father's legacy alive as he focused on helping in the house and teaching his little sister what father had taught him about trains. His mother's reaction turned what could have been a positive legacy into a negative one by discouraging his attempts to emulate his father. She would not let him teach his sister about the electric trains that father and son used to play with together. She thought Frank exaggerated his abilities to be helpful. She worried a good deal about her ability as a single parent to maintain control when Frank became a teenager. By the third interview Frank's CBCL scores are elevated into the clinical range and he complained that he feared mother would get lost when he went places with her.

\title{
Ignored the Effect of the Death
}

Few parents can actually ignore their child's behavior or the fact of the death in the family. But sometimes the parent's behavior seems to ignore the impact of the death. For example, Frank's mother knew that he needed to be seen by a doctor to begin treatment to prevent his developing the same condition that killed his father. 
In two years she had not done this. In this critical area she seems unable to recognize his special needs. She was also very angry with her husband who knew the dangers of his situation and postponed doing anything about it.

While Christie's father was able to say that he could not put himself in her place, he had difficulty seeing the impact of the death on her behavior. He said: "I can't imagine what it is like to lose a mother." He did not see her rebelliousness and her dropping out of school as connected to her mother's death. He talked about her as an adolescent who is trying to assert her independence, not as one who is grieving her mother's death. This father acts as if each of these are separate issues. Lisa left home, thus reducing family tension.

Even when their parent recognizes the impact of the death on their children, they cannot always act on what they see and know. Rita's mother describes her girls as like two orphans for whom father was always there. She is not blind to the children's pain:

I just hope that I can provide them with what they need emotionally and the guidance they need. Sometimes I don't know whether I'm being too strict, sometimes it is hard to say "no" because I feel like I have to sort of compensate for the loss of their father.

Yet she does not act on her concerns. When she comes home from work she spends her time in her room. While on one level she knows, on another she is very clear that "I don't know what Rita thinks so I can't help her." In this way she justifies her own withdrawal and justifies her actions.

\section{Feeling Helpless}

This way of coping may be a continuation of the style of coping of parents who were trying to ignore the effects of the death on their children. Some parents felt that they could not deal with the problems with which their children were confronting them. This was especially true where the legacy of the death involved the continuation of a dysfunctional or conflictual family environment. The surviving parent might recognize that there is a connection between the death and their child's feelings about the deceased, but felt helpless to do anything about it. Sometimes they seemed profoundly fatigued and felt defeated by their children. Jeffrey's mother knows that he is imitating his father in the way he treats her, but does not know what to do to change it. She talks of the chaos in her life and wants it to go away. She felt helpless to control the children's behavior:

I don't know how to treat someone who is hurting. I can't deal with my own feelings. The hardest thing for me is to feel like there isn't a lot of chaos here. I try to ignore it. I can't get the kids cooperation. They don't like to be told what to do.

Jodie's father was very aware of how much his children's behavior related to his wife's death, but seemed unable to respond to them constructively. All his children 
were at risk. While he cared passionately about his children, when his older children did not obey family rules his only solution was to send them to live someplace else. They went to a friend's family. He sought help from social workers and the mental health system for his children, but did not seem to understand that changing his own behavior could make a difference. He was unable to be proactive in his parenting, and instead focused on his fatigue and sense of helplessness.

In conclusion, our analysis of the data revealed two inter-related social constructions. First, we identified a pattern of legacies that the children maintained with their deceased parent that had the potential for having a negative impact on these children. Second we found that the way these legacies affected the child's life, in part, depended on their surviving parents' reactions. Some parents understood the concept of legacy, recognizing that how their children maintained a connection to the deceased made a difference in their behavior. The parent's ability or inability to reframe what could be a potentially problematic legacy moderated the impact for their children. These parents were often proactive, and defined the situation in ways that were helpful to their children. Other parents seemed more reactive, not always recognizing the connections between their children's behavior and their spouse's death. In many ways these parents felt ineffectual as well as helpless and were unable to bring about change in their situation. They did not appreciate the impact of the death or of the importance of what they did to affect their children's behavior. Finally, there were some families where surviving parents cast appropriate attachment to the deceased in a negative light.

\section{LIMITATIONS}

Negative legacies are not the sole factor in explaining these children's problem behaviors or the way they cope with the death of a parent. Other factors may contribute to the behaviors associated with elevated CBCL scores such as family and children's prior behavior problems.

There are also questions regarding the use of Achenbach Child Behavior Check List scores as the primary measure to identify children at greatest risk of having emotional difficulties. The Achenbach is a parent rating scale of child behavior, and reflects only the parent's perception of the child. Different studies have examined the limitations of parent ratings of children's behavior (Achenbach, McConaughty, \& Howell, 1987; Belle, 1999). In two-parent families, parents can differ from one another in their ability to accurately perceive and rate their children's behavior (Johnston, Gonzalez, \& Campbell, 1987). Thus, certain children with significant problems may not have been identified as high risk, because the CBCL, as used in the Child Bereavement Study, depended solely on the surviving parent's assessment. There were some children who were identified as high risk and who if other measures were used as well might not be. 
There were also children whose scores were not elevated who clearly displayed problem behavior that other measures might have revealed.

The categories that we identified, following the practice in using grounded theory, emerged as a result of our analysis and the consensus we arrived at when each of us were able to identify the same variables in a given family. A future study of the larger sample is needed to validate these categories and to see how pervasive they are. In addition, these categories by their very nature must be understood as reflecting these children's reactions two years after their parent's death. The analysis did not look at how these children's connections changed over time since the death. Now that we have identified these categories it would be important to review the data for the way these connections evolved over the two years.

\section{DISCUSSION}

This article, focusing on the concept of legacy, furthers our understanding of the concept of continuing bonds (Silverman \& Klass, 1996; Silverman \& Nickman, 1996). As we examine the larger context in which the bond grows, we can now identify not only the positive aspects of such a connection but also some of the negative. A legacy, as we are using the term, refers to one way that childrens' and adolescents' relationships with their deceased parents is expressed. The dictionary defines legacy as a gift, as in a will, something left to posterity or something coming from the past, such as money or personal property (Webster's Third International Dictionary, 1967). As it was used by Normand (1994) it refers to a relationship in which children consciously chose certain aspects of the deceased's personality or behavior to connect them to their deceased parent. She cites Vigotsky (Normand, 1994, p. 135) who wrote that "speech for self" serves the purpose of self-guidance. This internal dialogue is a primary source of our notions of self and the basis of self control. It is also the basis for the concept of legacy.

More needs to be known about this process of internalization and what aspects of the parent's behavior children choose to adopt. Children's changing ability to understand their relationship with their parent, given their age at the time of the death and the way they mature, will certainly influence what they remember, what they incorporate, and how they understand this process (Baker, Sedney, \& Gross, 1992; Christ, 2000; Silverman, 2000a). Children's ability to reflect on their experience and reactions is an indicator of where they are developmentally (Kegan, 1982; Silverman, 2000a). To see themselves as a living legacy, children need to reach a place where they have an awareness of their deceased parent as a person in this parent's own right. This is not always age related. Children need to be able to reflect on their own behavior and recognize the connections between what they are doing, who their parent was, how their activity gives continuing life to the parent and honors his or her life. 
This happens, at least in part, through the process of identification with the deceased (Baker, 2001). Identification as a process differs when a parent has died. With a living parent, children do not have to reach out to find ways of being connected. For better or worse, that parent is always there, interacting and reacting, and the process of how any given child will carry the parent within is influenced by their current interaction that is constantly being corrected and changing. When a parent dies, the continuing connection needs the reinforcement of a continuing conversation that often depends on where the children are developmentally, their position in the family, and how the surviving parent understands their own role in this ongoing conversation. Silverman (2000a) talked about child-centered and parent-centered approaches to parenting that seem to apply here. The parents whose children bore the negative consequences of their connections to the deceased seemed to be unable to put themselves in this particular child's shoes, and were more focused on their own needs and feelings. These were what Silverman called parent-centered parents.

These findings contrast to earlier findings (Normand, Silverman, \& Nickman, 1996) from the CBS. Other children in the CBS study, two years after the death, talked about themselves as their parent's living legacy. These were affirming connections that seemed to enhance the child's self-esteem and rooted the deceased in the child's current life in a positive sense. In contrast to parents in the new analysis, the surviving parents in Normand's sample helped their children remember the dead parent in a way that had positive consequences for the family and facilitated their mourning (Nickman, Silverman, \& Normand, 1998).

There are a variety of possible explanations as to why legacies become negative and lead to problems in these bereaved children, and why parental reactions would have a moderating effect on their children's behavior. We see this data exemplifying our view of grief. We see grief as an interactive process that can only be understood in the social context in which it occurs (Silverman, 2000a; Walter, 1999). As we look at the specific circumstances of the situation for the source of difficulty, we focus not only on the individual but on their relationships with others.

One circumstance we have identified is the genetic link in some of these illness. These are more likely to become negative depending on the parent's ability to empathize and take the role of their child at a time when they were themselves experiencing great pain around the loss. This ability can make the situation better or worse. We see varying degree of competency in this area (Allen \& Hayslip, 2000). These parents were more parent-centered. A negative legacy that stems from the deceased parent's illness-for example, an illness that the child believes he or she will also develop - can lead to the development of anxiety and phobic behavior in the children, who become hypervigilant for any signs that they too will become ill. Without parental understanding of their anxiety, along with clarification and reassurance that their fears will be taken seriously and their health will be carefully monitored, these fears and phobias can have a crippling effect on the child's developmental progress. 
Likewise, a child can identify with the role that was played by the parent in the past, and try to play out that role in the family after the parent's death. While this type of identification might make the child feel closer emotionally to the parent that died, taking on too arduous and demanding a role can compromise children's ability to strengthen age-appropriate interests and relationships. We see evidence that it is only the surviving parent, or in some cases another trusted family member, that can validate the child's own developmental needs and give the child permission and guidance to find a more appropriate way of connecting to the deceased. It is not clear why some parents are dismissive and ineffectual. We can assume that they are reacting to the loss in what may be a typical manner for them (Boerner \& Silverman, 2001; Silverman, 2000a), but it is beyond the scope of this article to say more about this.

This examination of the concept of legacies in part enables us to study the process of identification as it is occurring in the lives of these children, not through retrospective analyses as has often been the case in other studies (Furman, 1974). While identification is often described as an intrapsychic process which relies primarily on the child's own feelings and needs, our analysis of this data shows that this is often not the case. In the case of a parent who exhibited negative traits or behaviors prior to her or his death, a child may identify with those same negative traits after the parent's death. The surviving parent can moderate this process by highlighting positive as well as negative characteristics of the deceased parent, and thus help the child integrate both positive and negative in their image of the dead parent. In these families, identification becomes an interactive process involving not just the child's wish and need to identify with the parent, but the surviving parent's ability to encourage the child to integrate the different aspects of the deceased parent's legacy. Identification involves not just the child's memories and feelings, but requires the surviving parent's involvement as well. In conclusion, we know that legacies can provide children with comfort and solace as they find positive ways to affirm their connection to the deceased. This is often not possible, however, when their connection with the deceased is primarily characterized by negative qualities and implications. These kinds of connections along with parental behavior that is not helpful, seem to be associated with problem behavior in these children.

As we look at the implications of this analysis of the data we see the importance of providing support to families with dependent children after the death of a parent. Sandler and his colleagues (in press) talked about the need for increasing educational opportunities for developing parenting skills appropriate to the needs of a bereaved family. This article provides additional support for this recommendation.

\section{REFERENCES}

Achenbach, T. M. (1983). Developmental psychopathology (2nd ed.). New York: John Wiley. 
Achenbach, T. M., McConaughy, S. H., \& Howell, C. T. (1987). Child/Adolescent behavioral and emotional problems: Implications of cross-referent correlations for situational specificity. Psychological Bulletin, 101, 213-232.

Allen, S., \& Hayslip, B. (2000). Research on gender differences in bereavement outcome: Presenting a model of experienced competence. In D. Lund (Ed.), Men coping with grief (pp. 97-115). Amityville, NY: Baywood.

Ayers, T. S., Sandler, I. N., West, S. G., \& Roosa, M. W. (1996). A dispositional and situational assessment of children's coping: Testing alternative models of coping. Journal of Personality, 64(4), 923-958.

Baker, J. (2001). Mourning and the transformation of object relationships: Evidence for the persistence of internal attachments. Psychoanalytic Psychology.

Baker, J., Sedney, M. A.,\& Gross, E. (1992). Psychological tasks for bereaved children. American Journal of Orthopsychiatry, 62(1), 105-116.

Belle, D. (1999). The after-school lives of children: Alone and with others while parents work. Hillside, NJ: Lawrence Erlbaum Associates.

Boerner, K., \& Silverman, P. (2001). Gender specific coping patterns in widowed parents with dependent children. Omega, 43(3), 201-216.

Christ, G. (2000). Healing children's grief. New York: Oxford University Press.

Furman, E. (1974). A child's parent dies: Studies in childhood bereavement. New Haven, CT: Yale University Press.

Gersten, J. C., Beals, J., \& Kallgren, C. (1991). Epidemiology and preventive interventions: Parental death in childhood as a case example. American Journal of Community Psychology, 19, 481.

Glaser, B., \& Strauss, G. (1967). The discovery of grounded theory. Chicago: Aldine Press.

Harter, S. (1985). Processes underlying the construction, maintenance and enhancement of the self concept in children. In J. Sulo \& A. Greenwall (Eds.), Psychological perspectives on the self (pp. 138-181) Hillside, NJ: Lawrence Erlbaum Associates.

Johnston, J. R., Gonzalez, R., \& Campbell, L. E. G. (1987). Ongoing postdivorce conflict and childhood disturbance. Journal of Abnormal Child Psychology, 15, 493-509.

Kegan, R. (1982). The evolving self. Cambridge, MA: Harvard University.

Nickman, S. L., Silverman, P. R., \& Normand, C. (1998). Children's construction of their deceased parent: The surviving parent's contribution. American Journal of Orthopsychiatry, 68(1), 126-141.

Normand, C. (1994). A longitudinal analysis of bereaved children's continuing relationships to their deceased parents. Unpublished Ph.D. dissertation, Waterloo University, Waterloo, Ontario, Canada.

Normand, C., Silverman, P. R., \& Nickman, S. (1996). Bereaved children's changing relationship with the deceased. In D. Klass, P. R. Silverman, \& S. Nickman (Eds.) Continuing bonds: A new understanding of grief (pp. 87-111). Bristol, PA: Taylor and Francis.

Radloff, L.S. (1977). The CES-D Scale: A self-report depression scale for research in the general population. Applied Psychological Measurement, 385-401.

Rutter, M. (1983). Stress, coping and development: Some issues and questions. In M. Garmazy \& M. Rutter (Eds.), Stress, coping, and development in children (pp. 1-41). New York: McGraw Hill. 
Saldinger, A., Cain, A., Kalter, N., \& Lohnes, K. (1999). Anticipating parental death in families with young children. American Journal of Orthopsychiatry, 69(1), 39-48.

Sandler, I. N., Ayers, T. S., Wolchik, S. A., Tein, J. Y., Kwok, O. M, Haine, R. A., Twohey, J. L., Suter, J., Lin, K., Padgett-Jone, S., Weyer, J. L., Cole, E., Kriege, G., \& Griffen, W. A. (in press). The family bereavement program: Efficacy evaluation of a theory based prevention program for parentally bereaved children and adolescents. Journal of Consulting and Clinical Psychology.

Silverman, P. R. (2000a). Never too young to know: Death in children's lives. New York: Oxford University Press.

Silverman, P. R. (2000b). Research, clinical practice and the human experience: Putting the pieces studies together. Invited Paper for Special Issue of Death Studies, 24(6), 469-478.

Silverman, P. R., \& Klass, D. (1996) What's the problem? In D. Klass, P. R. Silverman, \& S. Nickman (Eds.), Continuing bonds: A new understanding of grief. Washington, D.C.: Taylor and Francis.

Silverman, P. R., \& Nickman, S. L. (1996). Children's construction of their dead parent. In D. Klass, P. R. Silverman, \& S. Nickman (Eds.), Continuing bonds: A new understanding of grief. Washington, D.C.: Taylor and Francis.

Silverman, P. R., \& Worden, J. W. (1992). Children's reactions in the early months after the death of a parent. American Journal of Orthopsychiatry, 62(1), 93-104.

Silverman, P., \& Worden, W. (1993). Children's reaction to the death of a parent. In M. Stroebe, W. Stroebe, \& R. Hansson (Eds.), Handbook of bereavement, Cambridge, England: Cambridge University Press.

Strauss A., \& Corbin, J. (1990). Basics of qualitative research. Newbury Park, CA: Sage.

Walter, T. (1999). On bereavement: The culture of grief. Buckingham, Great Britain: Open University Press.

Webster's Third New International Dictionary (1967). Springfield, MA: G. \& C. Merriam Co.

Worden, J. W. (1996). Children and grief: When a child's parent dies. New York: Guilford Press.

Worden, J. W., \& Silverman, P. R. (1993). Grief and depression in newly widowed parents with school age children. Omega, 27(3), 251-261.

Worden, J. W., \& Silverman, P. R. (1996). Parental death and the adjustment of school-age children. Omega, 27(3), 251-261.

\section{Direct reprint requests to:}

Phyllis R. Silverman, Ph.D.

18 Ingleside Road

Lexington, MA 02420

e-mail: silverman@helix.mgh.harvard.edu 